\title{
Knowledge, Attitude and Practice Towards Female Genital Mutilation Among Reproductive Age Women in Amad Imam Town, Jarso District, East Hararge Zone, Oromia Region, Ethiopia: A Community Based Study
}

\author{
Walellign Anmut ${ }^{1 *} \quad$ Tigistu Toru $^{2} \quad$ Addisu yeshambel $^{1} \quad$ Molalegn Mesele $^{1}$ \\ 1.Department of Midwifery, College of Health Science and Medicine, Wolaita Sodo University, Wolaita Sodo, \\ Ethiopia \\ 2.Department of Nursing, College of Health Science and Medicine, Wolkite University, Wolkite, Ethiopia
}

\begin{abstract}
Background: - Despite the widespread practice of FGM, not much attention had been given to it until recently. The attitude of expectant mothers towards it is crucial in sustaining it. It is practiced mainly in Africa and in some Asian countries.

Objective: - To assess knowledge, attitude and practice (KAP) towards FGM among the reproductive age women in Amad Imam town, Jarso district, East Hararge zone, Oromia Region.

Methods: - A community based cross sectional study was employed. Study was conducted from March 15 to April 1/2018. Systematic random sampling technique was used to select study subjects and data was collected by using pretested, structured questionnaire, translated to local language (Oromiffa).

Results:-A total of 264 female respondents in the reproductive age group (15-49 years) were interviewed with structured questionnaire. Prevalence of FGM in the study area was $91.28 \%$, where excision (type II) is the commonest type of FGM practiced. clitoridectomy and suni where reported $30.68 \%$ and $16.28 \%$ respectively. $178(67.4 \%)$ of the respondents had good knowledge on FGM,. and 188(71.2\%) of the respondent women had positive attitude towards FGM, and 30(11.36\%) had negative attitude towards FGM.

Conclusion:-FGM is common practice in the eastern Hararge Zone, East Ethiopia .There is a gap between knowledge of negative effect of the practice and positive attitude toward the practice to continue. Hence, wide information, education and communication recommended.
\end{abstract}

Keywords: female, genital mutilation, reproductive age, Ethiopia.

DOI: $10.7176 / \mathrm{JMPB} / 66-02$

Publication date:June 30th 2020

\section{Background information}

All societies have norms of care and behavior based on age, gender and social values. These norms are often referred to traditional practices which may be beneficial or harmful. Among the harmful traditional practices (HTPs), one deeply rooted that has numerous negative consequences on the health of girls and women is female genital mutilation (FGM) (1).

FGM is defined by world health organization (WHO) as 'all procedures involving partial or total removal of the external female genitalia other injury to the female genital organs whether for culture, religions or other nontherapeutic reasons. (2).

There are many reasons for performing FGM and they vary between settings, communities and countries, they can be summarized as relating to control of women and their sexuality, religion motivations, rites of passage, ideas of hygiene, to prevent masturbation, femininity and aesthetic and social pressures and expectations. Religion plays an important role in the persistence of FGM. It's predominant among Muslims but also occur among Christians (Coptic's, catholic and protestant), animist and Jews (the flashes in Egypt) (3-4).

FGM is a grave human right violation which is perpetuated by families in the name of culture, traditional and religion. The WHO estimates that globally from130-140 million girls and women's worldwide have been undergone some type of FGM. It has-been estimated that currently about three million girls, most of them under 15 years age, undergone the procedure every year. Which is approximately 8000 girls per day. The majority of it takes place in 29African countries but many immigrant communities continue practicing in Europe, North America, Australia and New Zealand (5).

The prevalence of FGM varies significantly from country to country from nearly $98 \%$ in Somali, $74 \%$ in Ethiopia, $5 \%$ in Democratic republic of Congo to less than $1 \%$ in Uganda. There is also wide variation by geographic regions and rural or urban residence within many countries. In most countries including Ethiopia, Liberia and Kenya the practice of FGM is more common in rural areas (4-6).

The practice of FGM is a big problem. Numerous international human right laws and conferences have highlighted the need to eliminate this practice. FGM violates the human rights of women and girls, causing physical and psychological harm, it also denies them the enjoyment of the highest attainable level of sexual and reproduction 
health. Furthermore, it is flexion of discrimination against women and girls (5).

Health consequences of FGM are immense and generally categorized into immediate and long term complications. Immediate complications include: death, hemorrhage, shock infection, septicemia and severe pain etc. Long-term complications include:- pain during sexual intercourse(dyspareunia),dysmenorrheal, infertility, problem during childbirth and pelvic inflammatory disease(PIDs) $(1,7)$.

A study done in Jigjig a town, Somalia region Ethiopia, January to May, 2012( $\mathrm{n}=323)$, shows the following FGM related complications: bleeding and pain during mutilation 107 (33.1\%), Infection and painful menstruation $170(52.6 \%)$, Pain during intercourse 34(10.5\%)Others $12(3.7 \%)(6)$. FGM practice is primarily found in areas where there is much poverty, high child and maternal mortality, illiteracy unsanitary conditions and where there is little health care facilities( 8$)$.

The rationale and the meaning behind the cultural significance of this harmful practice mostly resolve around social definition of womanhood and attitude towards women's sexuality. A common feature is the social conditioning of women to accept FGM within the social definition of women hood annoy identity. This led to perpetuate and defend the practice even if many of them acknowledge the dampening effect of FGM on women's sexual drive and reproduction function(9).For the reproduction and sexual rights of women and girls the implication off is significant $(2,10)$.

The practice of FGM is a national problem because not only does it affect the physical mental and social life of more than half of the population that is, women and children, it also affects the socio-economic development of the country (11).In Ethiopia FGM is widely practiced among all women and girls involving members of all regions and religion causing an extremely high rate of maternal mortality in the country. Approximately $74 \%$ of the Ethiopian women and girls have undergone the practice (11). The National Committee on Traditional Practice in Ethiopia (NCTPE) conducts many activities against FGM. the aim of the organization mainly lies on increasing the awareness of the adverse medical, psychological and social implication of Harmful traditional practices (HTPs) by distributing teaching material organizing workshops for influential target groups and training trainers $(9,11)$.

Despite the continues efforts against the practice made by governmental and Non-governmental Organization (NGOs), still there is gap in knowledge and understanding about the extent of the problem and successfully mans of interventions to eliminate the practice. More need to be done to tackle FGM. The lack of organized data on FGM makes it difficult for policymakers and professionals to respond effectively to the needs of affected women and to protect girls from undergoing FGM). There was no previous study done on this topic in the study area and the status of FGM was unknown. Therefore this research is designed to assess knowledge, attitude and practice of FGM among the reproductive age women in Amad Imam Town of Oromia Region.

\section{Objectives}

General Objective

To assess knowledge, attitude and practice towards FGM among the reproductive age women in Amad Imam town, Jarso District, East Hararge Zone, Oromia Region, East Ethiopia.

\section{Specific Objective:}

1. To assess the knowledge towards FGM among the reproductive age women.

2. To identify women's attitude towards FGM among the reproductive age women.

3. To assess practice towards FGM among the reproductive age women.

\section{Methods and Materials \\ Study area and period}

Amad Imam is a town on eastern part of Ethiopia. Located on the Jarso District, East Hararge Zone of the Oromia Region .the altitude of the town ranges from 1050 to 3030 meters above sea level and also $563 \mathrm{~km}$ far from capital city of Ethiopia, Addis Ababa. Economically primarily depends on farming and trade with neighboring District of south by Harari regional state, on the west by Konbolcha woreda, on the east by Gursum woreda and on the north by Ejarsa Goro town.

Based on figures from the central statistical agency in 2018 Amad Imam town has an estimated total population of 5,754, from these 2, 935 were females. There are 1, 273 households in district.

The health activities of the town are mainly carried out by one governmental Health center and there are few private health clinics. The study was conducted from March 15 to April 1/2018.

\section{Study design}

A Community based cross-sectional study design was employed.

Source and study population

Source population: -all women whose age 15-49 years in Amad Imam town. 
Study population: All selected women age group between 15-49 years.

\section{Exclusion and inclusion criteria}

Inclusion criteria

Reproductive age women (15-49 years) and willing to participate in the study

\section{Exclusion criteria}

Women who are sick during data collection period and living there less than 6 month were excluded

\section{Sample size determination}

The sample size were determine by using the formula for single population proportion $\mathrm{n}=\frac{(\alpha / 2)^{2} \times \mathrm{p}(1-\mathrm{p})}{\mathrm{d}^{2}}$

Where

$\mathrm{N}=$ Hose holds.

$\mathrm{n}=$ sample size

$\mathrm{P}=$ prevalence of FGM in Ethiopia= 0.74(Ref No 22 HDS 2005), $\mathrm{Z}=$ confidence interval, 1.96, $\mathrm{q}=1-\mathrm{p}=0.26$

$\mathrm{d}=$ margin of error

$$
\begin{gathered}
\mathrm{n}=\frac{(1.96)^{2} \times(0.74)(0.26)}{(0.05)^{2}} \\
\mathrm{n}=296
\end{gathered}
$$

Since the study populations were less than 10,000 we have used the correction formula

$\mathrm{n}_{\mathrm{f}=\underline{\mathrm{n}}}$

$\frac{1+\mathrm{n}}{\mathrm{N}}$

$\underline{\underline{296}}$

$+\underline{296}$

1273

$\mathrm{N}=1273$ (Hose holds).

$\mathrm{n}_{\mathrm{f}}=240$

Accordingly, the calculated sample was 240 adding $10 \%$ (24) of non-respondent rate the total sample size required for this study is found to be 264 women.

\section{Sampling procedure}

Systematic random sampling technique was employed, the sampling interval was determined by

$\mathrm{K}=1273=4.8=5$

$$
264
$$

women in every $5^{\text {th }}$ house was interviewed after identifying the first house by using lottery method from first up to $5^{\text {th }}$ house from the entrance of the town .when there was no women whose age 15-49 years ,the next household was substituted.

\section{Data collection Method}

Data was collected by using pretested, structured interview questionnaire by reviewing related literatures in English version. Data was collected by trained three diploma nurses and one supervisor after being briefed on the purpose of the study and on how to fill adequate information on the questionnaire.

\section{Data quality management}

The data collection tool was translated into local language, Oromifa by experts and was translated back to English by another person to ensure consistency and accuracy. Training was given to both the data collectors and supervisors for one day on the purpose of the study, data collection tools and procedure, handling ethical issues and maintaining confidentiality and privacy. Each supervisor and Principal investigator was supervised data collectors and checked all the filled questionnaires for completion, clarity and consistency on daily bases. The questionnaire was pre tested on 5\% of calculated sample size out the study area before two weeks of the main data collection. The validity of the tool was also approved by experts.

\section{Data Analysis}

The collected data were first checked manually for completeness, missed values, unlikely responses and then coded, entered using Epi data version 3.5.1. Then cleaned and analyzed using SPSS version 25. Descriptive statistics were 
computed to determine frequencies and summary statistics (mean, standard deviation, and percentage) to describe the study population in relation to socio-demographic and other relevant variables. Data was presented using tables, graphs and figures.

\section{Ethics approval and consent to participant}

Ethical clearance was obtained from the institutional Review Board (IRB) of Jimma University, institute of Health. Other necessary permission was gain from the town administrative office. Written and verbal consent was obtained from each participant after thorough explanation of the purpose and the procedures of the study. Participation in the study was on a voluntary base. All responses were kept confidential and anonymous.

\section{Operational definitions}

Female Genital Mutilation: all procedure involving partial or total removal of external female genitalia or other injury to the female genital organs whether for culture, religion or other non-therapeutic reason Knowledge: information and understanding about FGM which a person has/which a people have

Good knowledge: women who scores $>80 \%$ in knowledge questions.

Fair knowledge: women who scores $60-80 \%$ in knowledge questions.

Poor knowledge: women who scores $<60 \%$ in knowledge question.

Attitude: feeling towards FGM

Positive attitude: women who scores $>80 \%$ of attitude questions.

Neutral: women who scores $60-80 \%$ of attitude questions.

Negative attitude: women who scores $<60 \%$ of attitude questions

Practice: overt behavior related to FGM

Sunni: less severe form of FGM in which only tips of clitoris is removed.

\section{RESULTS}

All 264 female respondents were interviewed and making a response rate of $100 \%$.Majority of the respondents were found to be Oromo ethnic group 258(97\%). Majority of the respondents were found to be Oromo ethnic group 258(97\%). Mean age of interviewed women was 28years. Seventy three percent of the interviewed women were married. Regarding the occupational status of the respondent 188(71.2\%) were housewives. See Table 1

Table 1:- Distribution of the respondents by Basic socio-demographic characteristics, Amad Imam Town, Jarso District, East Hararge Zone, Oromia Region, Ethiopia, 2018

\begin{tabular}{|c|c|c|c|}
\hline \multicolumn{2}{|l|}{ Variable } & Number & Percent \\
\hline \multirow[b]{2}{*}{ Age group (in year) } & $15-29$ & 167 & 63.3 \\
\hline & $30-49$ & 97 & 36.7 \\
\hline \multirow{2}{*}{ Religion } & Muslim & 258 & 97.72 \\
\hline & Christian & 6 & 2.27 \\
\hline \multirow{4}{*}{ Marital status } & Married & 192 & 72.72 \\
\hline & Single & 46 & 17.42 \\
\hline & Widowed & 6 & 2.27 \\
\hline & Divorced & 20 & 7.57 \\
\hline \multirow{4}{*}{ Occupational status } & Housewife & 188 & 71.2 \\
\hline & Merchant & 31 & 11.74 \\
\hline & Civil servant & 10 & 3.78 \\
\hline & Student & 35 & 13.25 \\
\hline \multirow{5}{*}{ Educational status } & Illiterate & 143 & 54.16 \\
\hline & Read and write & 29 & 10.98 \\
\hline & Grade 1-6 & 50 & 18.93 \\
\hline & Grade $7-12$ & 32 & 12.12 \\
\hline & Grade $12^{+}$ & 10 & 3.78 \\
\hline \multirow{5}{*}{$\begin{array}{l}\text { Monthly income(source world bank } \\
\text { report } 2008 \text { ref no } 21 \text { ) }\end{array}$} & $<500$ & 75 & 28.40 \\
\hline & $500-990$ & 97 & 36.74 \\
\hline & $1000-1490$ & 31 & 11.74 \\
\hline & $1500-1990$ & 19 & 7.19 \\
\hline & $\geq 2000$ & 42 & 15.90 \\
\hline
\end{tabular}

FGM practice among the interview women was $91.28 \%$. The majority of women had undergone excision (type II) $43.93 \%$ followed by clitridectomy and suni which accounts $30.68 \%$ and $16.28 \%$ respectively and $199(75.37 \%)$ of the practitioners of FGM in the town are traditional birth attendants (TBA) and $42(15.9 \%)$ are Village women other than TBAS. Majority 116(43.9\%) of the respondents had undergone FGM at the age range 
of 6-10 years. The dominant decision makers' of FGM practiced in the family were Mothers 195 (74\%), (Figure $1)$.

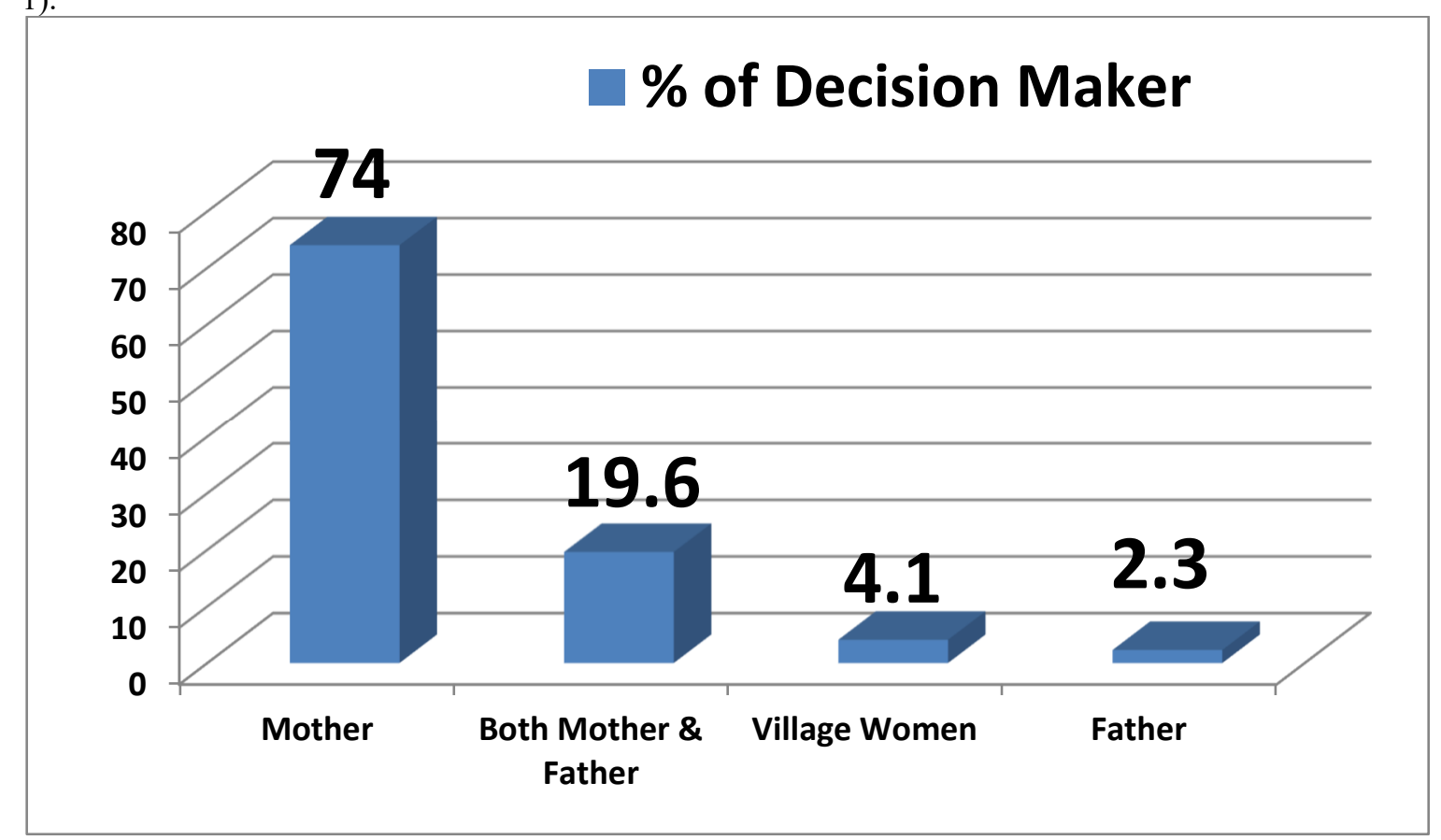

Figure 1: Decision maker for undergone FGM in the family among reproductive age women in Amad Imam town 2018.

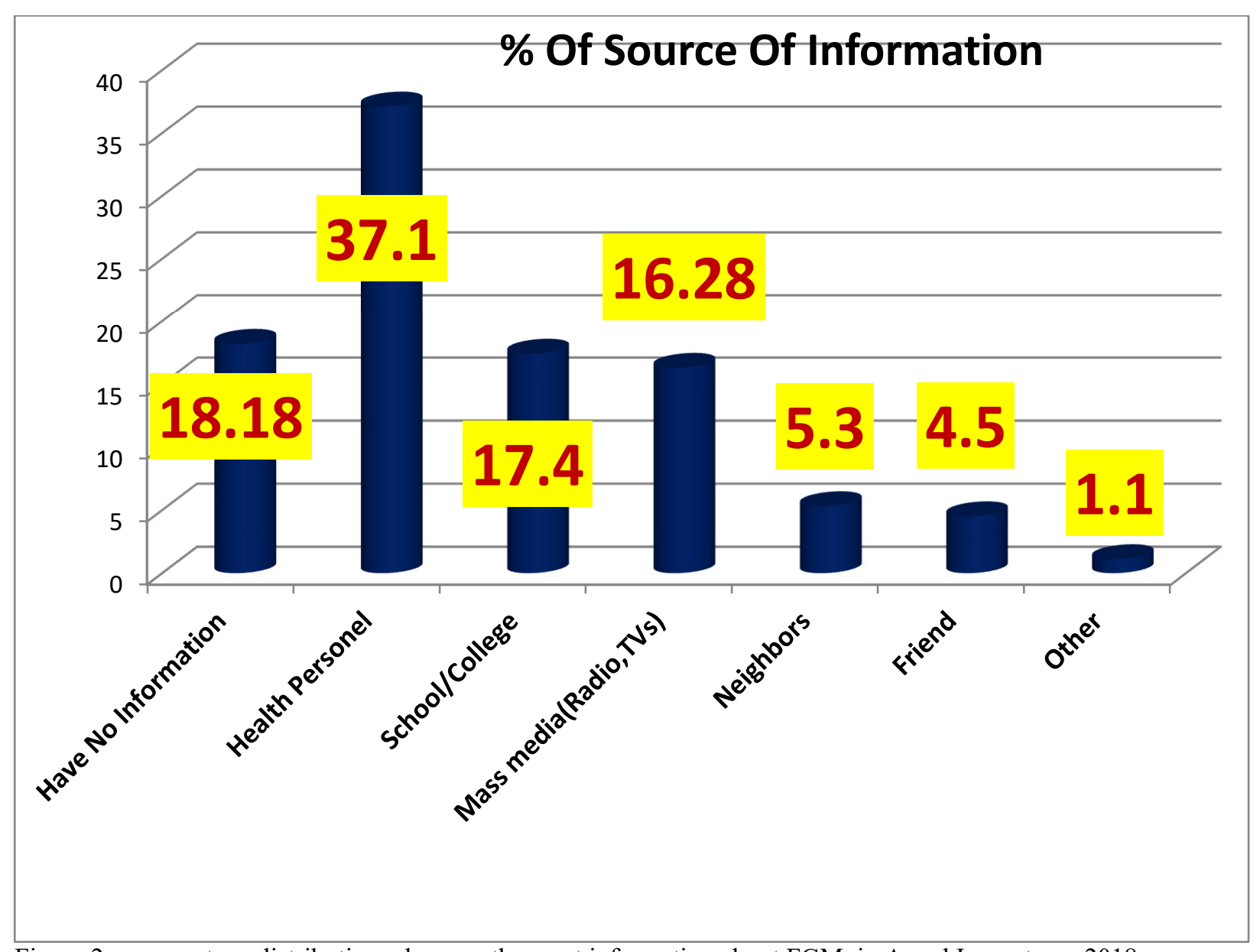

Figure 2: - percentage distribution where mothers get information about FGM, in Amad Imam town 2018. 
IN this study out of 264 mothers $216(81.81 \%)$ of them have got information about FGM and $48(18.18 \%)$ mothers have no information (Figure 2).

One hundred seventy eight (67.4\%) of the respondents had good knowledge level on FGM, 47(17.80\%) had fair knowledge and 39(14.7\%) had poor knowledge on FGM). Majority of the respondent had positive attitude 178(71.22\%) towards FGM (Figure 3).

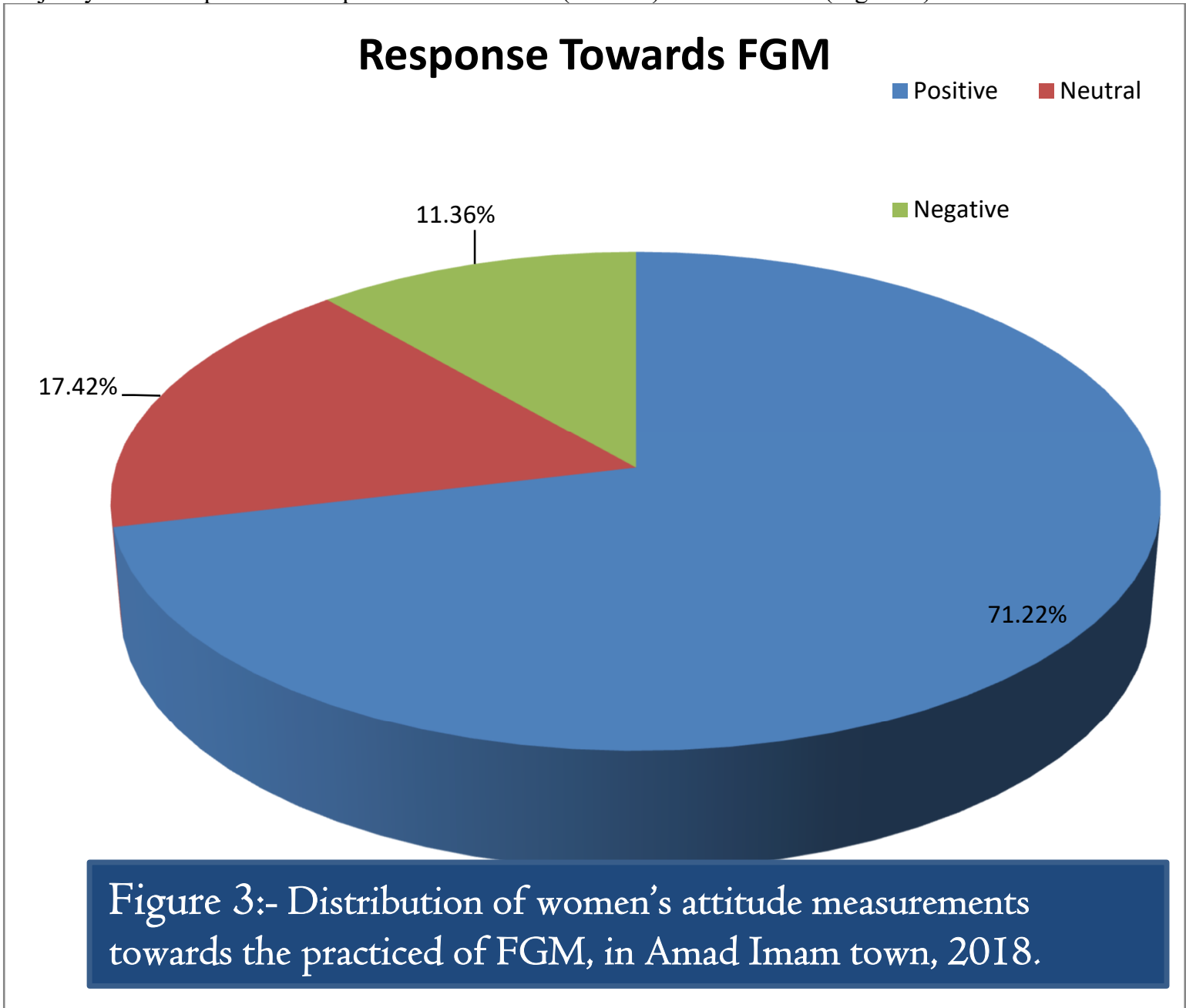

\section{DISCUSSION}

The prevalence of FGM in the study area was found to be $91.28 \%$ almost all women had undergone a form of FGM, the majority of them were undergone excision ( type II) $116(43.68 \%$ ) whereas $81(30.68 \%)$ and $43(16.28 \%)$ of them had undergone clitoridectomy and Sunni respectively. While in Ethiopia the prevalence of FGM is $74 \%$ and infibulations is practiced in Muslim regions bordering with Somalia, excision is the commonest type of FGM performed in other part of the country (11).

In a similar study in the Somali region of Ethiopia, an even higher prevalence of FGM 97\% was reported, Afar region $91.6 \%$. Among the four types of FGM type II is the commonest accounting $80 \%$ and the most extreme form, type III, constitutes 15\% which is higher in Djibouti, Somalia, North Sudan and parts of Ethiopia(Somalia and Afar regions) $(12,22$, and 23). The disparity observed on prevalence of FGM in Ethiopia might be due to socio- cultural differences of individual region within the country, socio demographic and sample size variation.

In this research $178(67.4 \%)$ of the respondents had good knowledge level on FGM, 47(17.80\%) had fair knowledge and 39(14.7\%) had poor knowledge on FGM). The study done in Jigjiga Town shows that $91.3 \%$ of the study participants had knowledge about FGM.

According to this study out of 264 women $30(11.36 \%)$ of them have Negative attitude towards the continuation of FGM while188 (71.2\%) of them have positive attitude towards the continuation of FGM. Similar study conducted in Serbo town showed that from 138 mother 112(81.22) of them have positive attitude towards the continuation of FGM and 26(18.8\%) them have Negative attitude towards the continuation of FGM (32). This similarity may be due to socio demographic and cultural similarity.

Study result in Prevalence of Female Genital Mutilation among the respondents and their age of Jigjig a town, 
Ethiopia, January to May, 2012 Age at which circumcision done 6-14 years43\% and 27.9\% had undergone the practice at the age of 1-5years.but in the study area $43.93 \%$ of the respondent were performed FGM at the age of $6-10$ years and $25.37 \%$ of them had undergone the practice at the age of $11-15$ years (6).

\section{CONCLUSION}

From this study it is generally concluded that FGM is practiced by every women in the study area with different form and the majority had undergone excision (type II). The majority of respondents in the study area had good knowledge 178(67.4\%) about FGM. Regarding to the attitude of women towards FGM $184(71.2 \%)$ of them had positive attitude towards FGM.

\section{DECLARATIONS}

\section{ABBREVIATIONS}

CBE: Community Based Education, CSA: Central Statistical Agency, DHS: Demographic Health Survey, EGLDAM: Ethiopian Association to Eliminate Harmful Traditional Practices ETB: Ethiopian Birr, FGM: Female Genital Mutilation, Forward: Foundation for Women's Health, Research and Development, HIV/AIDS: Human Immune Virus /Acquired immune deficiency syndrome, HTPs: Harmful Traditional Practices, JU: Jimma University

\section{Declarations}

\section{Ethics approval and consent to participate}

Ethical clearance was obtained from the institutional Review Board (IRB) of Jimma University, institute of Health. Other necessary permission was gain from the town administrative office. Written and verbal consent was obtained from each participant after thorough explanation of the purpose and the procedures of the study. Participation in the study was on a voluntary base. All responses were kept confidential and anonymous.

\section{Funding}

The research was not funded by any organization.

\section{Availability of data and materials}

All data and materials in this manuscript are available from the corresponding author on reasonable request.

\section{Authors' contribution}

TT and WA contributed in planning and organizing the study, collecting and analyzing the data, drafting the manuscript, reviewing and approving the final manuscript for publication. AY and MM contributed in analyzing the data, writing and reviewing the manuscript.

\section{Competing interest}

Authors declare that they have no competing interests.

Consent for publication

Not applicable.

\section{Authors' details}

TT: Lecturer at Wolkite University, Department of Nursing, And WA: Lecturer at Wolaita Sodo University, department of midwifery.

\section{ACKNOWLEDGEMENT}

We would like to express our deepest heartfelt thanks to Jimma University for allowing the conduct of this study. We would like to acknowledge town administrative office for their positive responses to facilitate this study. Our special thanks also go to study participants, data collectors and supervisors.

\section{References}

1. Taubian, I Letts. Female genital mutilation an overview Geneva WHO (update 2008)

2. Momoh, comfort (end).''FGM', Radcliffe Publicizing, 2005, PP.6-7

3. De briny. Discussion paper socio cultural aspects of FGC in lye E, De Brunei were Eds. Proceeding of the expect meeting on FGM .Ghent-Belgium, Nov 5-7, 1998

4. FMGC' country profile 'UNICEF, 22 July 2014.p.4\4of each profile

5. Hussein et al. Knowledge attitude and practice towards FGM among women in Jigjig a Town, Eastern Ethiopia Gaziantep Medical Journal.2013; 19(3); 164-168

6. Elizabeth. Social, cultural and ethnic factors determining the practice of FGM in Ethiopia thesis the degree of Master of Science, Canada, 199

7. Jacque smith description of phenomenon of FGM an international survey set 1995.

8. National committee in Traditional practices in Ethiopia, Addis Ababa, 1995

9. The lancet.com/journals/lancet/article/piiso140-6736(00)02453-3/full tat 22.28 TOO MANY 2013, FGM let us end it, DHS, 2005 and EGLDAM 2008 (WWW.egldam.fgm.net

10. Yirga et al Female Genital Mutilation: prevalence, perceptions and effect on women's health in Kersa district 
of Ethiopia. International Journal of Women's Health.2012; 4; 45-5

11. WHO, 2O11un update FGM progress report.FGM and obstetric outcome (Lancet, 2006, 367; 1835-1841)

12. Shaye J.d.cohen, why are not Jewish women circumcised? University of California press, 2005, P.59; Adele Berlin.

13. Arabian, S.A and Rouzi, sexual function in women with FGM ( 93),722-724 27.Berg, R.C; and Denisan,E(2012).does FGM affect women's' sexual functioning

14. The day I Saw 248 girls suffering genital mutilation Abigaint Haworth, The Guardian United Kingdom, (NEV 17 2012)29. Paschal et al. (2012) related factors of FGM in Ravens (Iran); Journal of women's health care.30. Prevalence of FGM UNICEF, Retrieved 18 August 2014

15. FGM/C: A statistical expirations UNICEF (2010); see Table 1c, pp. 34

16. ArgawA' 'etal", prevalence of FGM and attitude of mother toward Serbo town ,Ethiopia Journal of health science vol. 12(2)July 2002p59-65. 